\title{
The President and the Man on the Street: Definite Descriptions and Proper Names aCross Possible SITUATIONS*
}

\author{
Daniel Rothschild, \\ Princeton University \\ drothsch@princeton.edu
}

\begin{abstract}
Kripke's "modal argument" uses consideration about scope within modal contexts to show that proper names and definite descriptions must be of two different semantic types. I reexamine the data that is used to motivate Kripke's argument, and suggest that it, in fact, indicates that proper names behave exactly like a certain type of definite description, which I call "particularized" descriptions.
\end{abstract}

Many people draw a sharp contrast between the way speakers use names to talk about individuals and the way they use definite descriptions to do so. A proper name is used to pick out one specific individual. A definite description, on the other hand, provides a general formula for picking out distinct individuals in different situations. Metaphorically, a name is a tag attached to an individual, whereas a definite description is a set of instructions for finding an individual that satisfies some criterion.

This difference between names and descriptions is said to account for a well-known fact: descriptions exhibit narrow-scope readings with respect to modal operators while names do not. Here is an example in which a definite description has what is normally considered a scope ambiguity with a modal operator.

(1) Mary-Sue could have been married to the president.

Imagine (1) being uttered in a situation in which Grover Cleveland is the president. On one reading, (1) could be made true by a possible situation in which a) Grover Cleveland is married to Mary-Sue and b) Grover Cleveland is not president. This is the wide-scope reading of "the president" since it picks out the individual satisfying the role in the actual world, regardless of whether he satisfies it in the possibilities considered. On another reading, (1) could be true because of a possible situation in which Mary-Sue is married to someone else, say Jake, who is president in that possible situation. This is the narrow-scope reading of "the president" since the description picks up its referent within the possible situation considered.

Consider, by contrast, what happens if we replace the description in (1) with a proper name:

(2) Mary-Sue could have been married to Grover Cleveland.

There is no way of understanding ?? as having two different readings analogous to those of (1). Even if, as a matter of their syntax, proper names can have different scope with respect to modal

${ }^{*}$ I am indebted to Jessica Boyd, Sam Cumming, Delia Graff, Gilbert Harman, Irene Heim, Nathan Klinedinst, Margaret Miller, Jim Pryor, Philippe Schlenker, Brett Sherman, and Edwin Williams for helpful comments on earlier drafts and/or discussion of these topics. I am also grateful to the audience at Sinn und Bedeutung for many interesting comments and questions, not all of which are addressed here. 
operators, there are no different truth-conditional readings corresponding to the different scopes the name can take.

The standard picture of names and descriptions explains this difference between them. Modal operators are generally taken to quantify over different possible situations. Since names are tags linked to individuals while descriptions are instructions for finding an individual in a given situation, only the latter can pick out different individuals across different possible situations. This line of reasoning forms the basis of Kripke's famous modal argument for the claim that names cannot be semantically equivalent to descriptions (Kripke 1972) 1

This paper centers on a simple observation: scope ambiguities between definite descriptions and modal operators are only sometimes available (or, at least, are only sometimes apparent). It turns out that the narrow-scope readings of definite descriptions within modal operators are only available when the common ground - the mutual beliefs of the conversational participantsincludes the proposition that across a wide range of possible situations the descriptive content has a unique satisfier.

The the behavior of definite descriptions under modals to the contemporary debate about the semantics of proper names. I argue that the modal argument against descriptivist theories of names loses its force once we take into consideration the fact that many definite descriptions systematically fail to show narrow-scope readings. To make this point, I consider a treatment of proper names which construes them as linguistic devices akin to definite descriptions. According to this picture, both types of expressions are used to pick out individuals that satisfy some descriptive content. I show that this account accurately predicts the behavior of names with respect to modal operators.

\section{Descriptions Under Modal Operators}

First, we need to look at the details of the interaction of definite descriptions with modal operators. The key observation here is that definite descriptions have distinct wide- and narrow-scope readings with respect to modal operators. Although this observation plays a central role in much of the philosophical discussion of names and descriptions, there is little in the way of detailed study of the phenomenon. ${ }^{2}$

It will be useful to think of modal operators—like "must" and "might" — as quantifiers over possible worlds (or situations). To say that something must happen is to say that in all possible worlds it does happen. To say that something can happen is to say that there is a possible world (or situation) in which it does happen. Of course, modality comes in different flavors: modal operators may be read metaphysically, epistemically, or deontically. In this paper, I will concentrate on metaphysical modals-in keeping with much of the philosophical literature on names, descriptions, and modals.

Let's consider an example in order to get a grip on the narrow-scope readings of definite descriptions with respect to modal operators:

\footnotetext{
${ }^{1}$ The modal argument is widely discussed in the philosophy of language (Linsky 1983, Soames 2002, Stanley 1997).

${ }^{2}$ Within the semantics literature most discussion of the interaction of descriptions and modals centers around the phenomenon of modal subordination. Here is an example of modal subordination:

A bear might come in to the cabin. The bear would eat you.

The modal in the second sentence, although universal in force, is only interpreted relative to the worlds involving the possibility mentioned in the first sentence (Roberts 1989). In this paper, I will not discuss either this phenomenon or anaphoric uses of definite descriptions like the use of "the bear" in the second sentence, which refers back to the indefinite "a bear" in the first sentence.
} 
Aristotle might not have been the teacher of Alexander.

If we read the modal as having a metaphysical force, it is natural to think that (2)] is true. But since Aristotle was the teacher of Alexander, the sentence can only be true if the description "the teacher of Alexander" picks up its reference under the modal operator. In other words, "the teacher of Alexander" must pick out different individuals in the different worlds over which the modal operator quantifies. The truth of (2) is then established by the existence of a possible world in which the description "the teacher of Alexander" picks out someone besides Aristotle. In that possible world, Aristotle is not the teacher of Alexander. By contrast, the wide-scope reading of the description could not possibly be true. This is because, on the wide-scope reading, "the teacher of Alexander" picks out its referent in the actual world. But, in this case, it picks out Aristotle and the sentence would then assert that in some possible world Aristotle is not Aristotle, which is false.

Before moving on let me make a cautionary note. Sometimes the narrow-scope reading of a sentence containing a description and a modal may not be distinguishable from the wide-scope reading. If the sentence only quantifies over possible worlds across which one and the same person satisfies the description, it will be impossible to tell from the truth-conditions of the sentence whether the description within it takes narrow or wide scope. For this reason, all of my claims about when we can or cannot get a narrow-scope reading of a sentence apply only to contexts in which the different scopes have an effect on the truth-conditions of the sentence.

\subsection{Role-type vs. Particularized Descriptions}

Example (2) in the previous section demonstrates that some definite descriptions have narrowscope readings under modal operators. But the modal argument, as we shall see, relies on the claim that this is generally true of definite descriptions and this is the claim I wish to dispute. In order to do so, I need to make a distinction between two kinds of definite descriptions, which I call role-type and particularized descriptions.

A description is a role-type description if it is part of the common ground that there is exactly one person (or one salient person) satisfying the descriptive content across a range of relevant metaphysically possible situations and that the satisfier sometimes varies from situation to situation 3 Some examples of role-type descriptions are "the family lawyer," "the mayor," "the president," "the tallest pilot," and "the director." With role-type descriptions, we usually know independently of the specific conversational situation that the descriptive content is satisfied uniquely across other possible situations: It is part of general knowledge that cities generally have one mayor, countries one president, and so on. Of course, many role-type descriptions are incomplete in the sense that they need to be augmented by an implicit specification of the particular role in question - so, for instance, "the president" might be used to mean "the president of the US" or the "the president of the board of trustees." Likewise superlative descriptions, such as "the tallest man," require some domain within which they operate: "the tallest man" might mean "the tallest man in the room," or "the tallest man in the galaxy." But the basic criterion stands: a role-type description is a description for which it is part of the common ground both that the content of the (completed) description is uniquely satisfied across a wide range of possible situations and that the satisfier varies amongst these situations.

Particularized descriptions are simply those descriptions that are not role-type descriptions. The mark of a particularized description, then, is that it is not part of the common ground that the descriptive content has a unique but varying satisfier across a whole range of relevant meta-

\footnotetext{
${ }^{3}$ Note that while the number of metaphysically possible situations may be great, only certain situations are relevant when we use modals in normal speech with their metaphysical force.
} 
physically possible situations. Descriptions whose only content consists in general properties shared by many different individuals tend to be particularized descriptions, such as, "the tall boy," "the dog," and "the loose-fitting cap." Descriptions that refer to people by their physical location or what they did at some point are also usually particularized, such as, "the man I met yesterday," "the person over there," and "the cat in the basement." The reason these descriptions count as particularized - in ordinary contexts - is that we can only know that there is a single most salient individual satisfying the descriptive content (and thus the description picks some individual out) by having some sort of knowledge particular to the narrow conversational context (e.g. for "the tall boy" we must know that there happens to be exactly one tall boy around). I might further note that particularized descriptions may also be "incomplete" in the sense that one might naturally fill out descriptions like "the tall man" with extra information such as "in this room.' 4

Whether a description counts as particularized or role-type depends upon what the common ground is. This means that corresponding to almost any particularized description there is some conceivable conversational context in which that description would count as a role-type description, and vice versa. So the distinction is not one between different types of linguistic expressions, but between different types of expression/context pairs. However, certain descriptions cast themselves more naturally as one sort or the other. When I give an example it will be clear if I mean it to be particularized or not.

It is worth noting that the role-type/particularized distinction is not the famous distinction between referential and attributive uses of descriptions introduced by Donnellan (1966). On Donnellan's scheme, roughly speaking, attributive descriptions are used to speak of whoever satisfies the predicative content of a description, whereas referential descriptions are used to refer to known individuals. Whether a definite description falls on one side or the other of Donnellan's distinction depends on how it is used; how it is classified according to my distinction depends, instead, upon the relationship between the common ground and the predicative content of a description. Classification according to my distinction is independent of how a description is used, and, so, is independent of how it sits with regard to Donnellan's distinction. (But there may be points of contact. For instance, when a description is used attributively the conversational participants typically assume, or pretend to, that across different epistemically or different metaphysically possible situations different individuals would satisfy the descriptive content ${ }^{5}$ Thus it may be that attributive uses are only possible with role-type descriptions.)

\subsection{Role-type and Particularized Descriptions with Modals}

Now, as we have seen, role-type descriptions allow narrow-scope readings with respect to modal operators, as in (2), repeated here:

Aristotle might not have been the teacher of Alexander.

The description from ??, "the teacher of Alexander" can easily be a role-type description since it can be part of the common ground that across a wide range of possible worlds Alexander would have had a teacher, but not necessarily the same teacher (for example, a different student of Plato might have been chosen instead to be Alexander's teacher). The question I turn to now is whether particularized descriptions exhibit the same sort of behavior with regard to modal

\footnotetext{
${ }^{4}$ How incomplete descriptions are dealt with is a matter of much controversy within formal semantics and philosophy of language (Soames 1986).

${ }^{5}$ I think one can generalize the notion of role-type and particularized descriptions to epistemically possible situations in addition to metaphysically possible ones, though I do not explore that here.
} 
operators as role-type descriptions do.

Let's look at an example. Suppose that I went to a reception at the Met last night. At the reception, we can suppose, I talked to many different people for brief periods of time. Now, suppose that I learn that my old friend Hans was due to come to the reception but that he didn't make it because his plane was delayed. Let us suppose that for this reason it is a relevant possibility that Hans could have made it to the reception, and that, if this were the case, I would have talked to him all night at the reception. This possible situation, if it were actual, is one which I could aptly describe with this sentence:

Hans is the person I talked to the whole time.

Now suppose that I want to express to someone at the party that I consider (3) to be a possibility. One might think that I could do this by uttering a version of (3) with a possibility modal:

Hans might have been the person I talked to the whole time.

There is, however, something very odd about using ?? to express the possibility of a situation in which (3) is true (assuming there is actually no one who I talked to the whole time). Indeed, if I utter ?? at the party, I will probably confuse my audience. (I will discuss a bit later how one might try to make sense of such utterances.) This oddness is quite surprising, however. If the definite description "the person I talked to the whole time" can have scope within the modal operator, then we would expect that ?? would express the possibility of a situation within which (3) is true. Since such a situation is possible we would expect the utterance to be not only felicitous but also true. However, for some reason this narrow-scope reading of the description "the person I talked to the whole time" is not actually available ${ }^{6}$ (The wide-scope reading of the description is quite hard to get as well since there is no person in the actual situation the description could refer to.)

Let's consider another example. Suppose that throughout an entire dinner party Siegfried does not eat anything, and is unique in this regard. Suppose that I have another friend, say Siegmund, who also would not have eaten anything if he had been at the dinner. Now, suppose I say something like this:

(7) I might have enjoyed talking to the person fasting through the dinner.

It does not seem like I could mean anything but that I might have enjoyed talking to Siegfried by an utterance of (4). This is true even if it is is possible that Siegmund could have come and Siegfried not come. In this possible situation, of course, Siegmund would have been the only person fasting. Nonetheless, it does not seem like (4) can easily express the proposition that there is a possible situation in which I would have enjoyed talking to whoever was unique in fasting at the dinner, Siegmund, Siegfried or someone else entirely. In this respect we cannot easily get the narrow-scope of the description "the person fasting through the dinner."

We can, however, create conversational backgrounds within which "the person I talked to the whole time" has a narrow-scope reading in ?? and "the person fasting through the dinner" has a narrow-scope reading in (4), First take ?? again:

(8) Hans might have been the person I talked to the whole time.

\footnotetext{
${ }^{6}$ Those familiar with presuppositions may not be surprised by this, since this is, roughly speaking, predicted by the presuppositional theory of descriptions.
} 
Suppose that it is part of the common ground that I generally talk to one person throughout an entire evening (because, for instance, I always start an argument with someone about politics which lasts the whole evening). In this case, I could utter ?? in order to express the proposition that if Hans had come he would have filled the role of being the person I talked to all night. However, this is a case in which "the person I talked to the whole time," which would usually be a particularized description, acts as a role-type description since it indicates a role which is uniquely filled across many relevant counterfactual situations. 7

The situation is similar for (4). If we can take it for granted that there is usually exactly one person fasting at such dinners, or that the organizers had intended to invite exactly one person who wouldn't eat, though not any specific person, then the narrow-scope reading of (4) is available. However, without such an assumption the reading is very hard to get.

We have seen, then, that in order to get a narrow-scope reading of a definite description we need to treat it as a role-type one. Sometimes in response to an utterance the audience changes their assumptions, and, hence the common ground through the process of accommodation (Lewis 1983, Stalnaker 2002). This process of accommodation can lead the audience to treat a description as a role-type one even if prior to the utterance it is not part of the common ground that the description designates a role. Here is an example in which such accommodation might occur. Suppose I utter ?? when discussing a party I have just been to:

If I had gotten there earlier I might have been the person in charge of hats.

My audience would not take me just to be asserting that if I had gotten to the party earlier I would, by myself, have taken charge of the hats. Rather, they must also assume that across a whole range of different possible ways in which the party could have transpired there would have been one person who saw to the hats. Making this assumption, through accommodation, the audience can then understand my assertion in ?? to be the assertion that if I had gotten to the party earlier I would have played the role of dealing with the hats.

To understand better the behavior of descriptions within modal operators it is worth comparing sentences with particularized descriptions with sentences containing a typical role-type description. Here is one:

Adlai Stevenson could have been the president.

There is a natural reading of (5) on which the role-type description "the president" has narrow scope. It is true, for instance, if there are relevant possible worlds where Stevenson beats Eisenhower. These are worlds in which Stevenson is "the president." But that sort of reading, i.e. the narrow-scope one, is exactly the reading we do not find for ??, (4), or ?? without choosing backgrounds in which the descriptions act as role-type ones.

These observations about the scope of particularized and role-type descriptions beg for any explanation. Unfortunately I think the details of such an explanation will take us too far afield

\footnotetext{
${ }^{7}$ I can only think of one other circumstance in which the description "the man I talked to the whole time" could have a non-rigid, narrow scope in an utterance of ??. This other case is the one in which the description "the person I talked to the whole time" has already been introduced in either its definite or indefinite form in the conversation. For instance, instead of just saying ?? I might have said ??:
}

(i) I could have talked to a person the whole time. Hans might have been the person I talked to the whole time.

If I utter ?? it seems that the description in the second sentence can have a narrow-scope reading, and thus the utterance might express something true. However, in this case, the definite description is anaphorically linked to the indefinite description that precedes it. I want to put aside these anaphoric uses of descriptions as they involve the description inheriting properties from the original use. 
and are not pertinent in reassessing the modal argument. Unsurprisingly, I think facts like these need to be explained in terms of the theory of presuppositions. The Russellian account of definite descriptions, as far as I can tell, can give us no leverage on the different availability of the narrow- and wide-scope reading of definite descriptions within modal operators. Indeed, whether we should describe the difference in terms of scope rather than in terms of a worldvariable in the description itself seems to me an open question 8

\section{Proper Names and the Modal Argument}

An extremely influential argument in the philosophy of language, Kripke's modal argument, purports to show that proper names are not semantically equivalent to definite descriptions 9 Here is one version of the argument:

1. Definite descriptions exhibit narrow-scope readings with respect to modal operators.

2. Proper names do not exhibit narrow-scope readings with respect to modal operators.

3. The meaning of a proper name cannot be the same as that of a definite description.

The argument depends upon the sort of observations I made in the introduction to this paper. Consider, for instance, ??, repeated here:

Mary-Sue could have been married to Grover Cleveland.

The modal argument begins by suggesting that on the hypothesis that "Grover Cleveland" is really semantically equivalent to some description, "the F," one should expect to find two possible readings of ??, corresponding to whether the description, "the F," gets its scope under the modal (finding the satisfier of the description within each possible situation) or outside the modal (picking out its actual satisfier, i.e. Grover Cleveland). However ?? does not seem to exhibit different readings of this sort. So, the argument concludes, "Grover Cleveland" cannot be equivalent to "the F."

Many have noted that the argument only shows that proper names are not semantically equivalent to those descriptions whose descriptive content allows them to pick out different objects in different possible situations. In other words, the argument shows that proper names are not equivalent to those descriptions whose descriptive content is actually capable of being satisfied by different individuals in different situations. Some descriptions do not have this property. These include descriptions whose descriptive content contains some indexical reference to the actual world. No matter what their scope is, such descriptions always pick out the same individual (they are so-called rigidified descriptions). In light of this qualification, we can view the modal argument as purporting to establish that, if proper names are semantically equivalent to any definite descriptions, they are semantically equivalent to rigidified descriptions like "the actual mayor.' 10

The first premise in my presentation of the modal argument above states that definite descriptions exhibit narrow-scope readings with respect to modal operators. In this paper, however, I have presented and explained a significant qualification to this claim. I have shown that only

\footnotetext{
${ }^{8}$ An excellent discussion of the issues involved here and the problems for the Russellian rather than presuppositional view is to be found in chapter 3 of Elbourne (2005) (in particular, pages 109-112).

${ }^{9}$ Three pieces that seem to understand the argument this way are Linsky (1983, ch. 7), Stanley (1997), and Soames (2002, ch. 2).

${ }^{10}$ Discussion of rigidified descriptions include Nelson (2002), Stanley (1997), and Soames (2002).
} 
role-type descriptions can have narrow scope with respect to a modal operator. Thus, we need to revise our assessment of the modal argument in light of this qualification. 11

In fact, once we recognize that definite descriptions do not always exhibit scope ambiguities with respect to modal operators, the modal argument loses much of its force against descriptivist accounts of names. If one assumes that descriptions always exhibit scope ambiguities, then one instance of a sentence containing a proper name and a modal operator that does not show a scope ambiguity will serve to demonstrate that names cannot be descriptions (except perhaps rigidified descriptions). But, once we have recognized that descriptions do not generally show scope ambiguities, we can no longer reason in this way. Many definite descriptions, such as "the man in the corner" and "the person I saw yesterday," have restrictions on what scope they can get with respect to modal operators. These descriptions belong to the large class of descriptions that are particularized in most contexts and, thus, do not exhibit narrow-scope readings in these contexts. The modal argument fails to show that proper names are not equivalent to these sorts of descriptions.

It's worth noting that this is a significantly larger qualification than the one in the previous section about rigidified descriptions. Descriptions like "the man in the corner" are not rigidified descriptions since they have a predicative content which different individuals can satisfy in different situations. So, the class of definite descriptions that are generally particularized includes descriptions which are not rigidified. In addition, while it's extremely hard to find real English expressions that act as rigidified descriptions ("the actual mayor" certainly doesn't), it's extremely easy to find English expressions that are usually particularized descriptions.

Another way of putting my basic point is to say that the modal argument still leaves open the possibility that names are particularized descriptions. Of course, whether a description is particularized or role-type depends upon the relationship between the common ground and the predicative content of the description. So, a name is unlikely always to be a particularized description, but a name might be equivalent to a definite description that has a descriptive content which makes it particularized in most contexts. This hypothesis would explain the resistance names show to taking narrow scope in most instances.

In the remainder of the paper I examine one particular descriptivist conception of names to see whether, according to this conception, names can be construed as particularized descriptions. I will also look at contexts in which, according to this descriptivist proposal, names do not act as particularized descriptions. By looking at these contexts we can assess whether, as the descriptivist should predict, names can sometimes get narrow scope with respect to modal operators. I will argue that — contrary to the philosophical orthodoxy—-the descriptivist view does extremely well at predicting the potential scope of proper names with respect to modal operators.

\section{Names as Metalinguistic Descriptions}

The view that names are semantically equivalent to definite descriptions is often described as the view that names are disguised descriptions, since unlike real definite descriptions names do not openly show their descriptive content. This leads to the question of what the descriptive

\footnotetext{
${ }^{11}$ Kripke explicitly acknowledges the degree to which his argument depends on descriptions acting Russellian, and hence being able to get narrow scope (Kripke 1972). Geurts (1997) also picks up on this issue, arguing that names are like certain descriptions which always take wide scope (though he does not offer an account of why these descriptions take wide scope):
}

The presuppositions triggered by names seem to have a decidedly stronger tendency to 'take wide scope' than some others. In this respect, too, they are on a par with other descriptively attenuate 'incomplete', definites like 'the door' or anaphoric pronouns like 'it'. (p. 18) 
content of a name is. Here I will sketch one answer to this question, but I will not systematically consider alternatives.

One of the most plausible instantiations of the view that names are descriptions treats names as "metalinguistic" descriptions. $\sqrt{12}$ On this account, the meaning of a name $N$ is roughly captured by the description "the bearer of $N$." We must distinguish this account of the semantics of proper names from the truism that a name $N$ refers to whoever is referred to by $N$. The view that names are metalinguistic descriptions, unlike this truism, is neither trivial nor circular. We have a social practice of naming, under which one cannot bear a name just in virtue of some person using it to refer to you. So the facts about name-bearing are not mere trivial metalinguistic ones, like the fact that "jump" means jump. In fact, the metalinguistic view of names makes a very strong claim: that each proper name has the same meaning as some particular definite description.

Definite descriptions trigger presuppositions; so, if proper names are equivalent to certain definite descriptions they will also trigger presuppositions. Earlier, I suggested that definite descriptions trigger the presupposition that there is a uniquely salient individual satisfying the descriptive content. So, if a name $N$ were equivalent to the description "the bearer of N," then a use of $N$ would trigger the presupposition that there is a uniquely salient person bearing $N$. It seems plausible that names carry this presupposition. For when we use a proper name usually we presuppose that there is a most salient person bearing the name. Without this presupposition we could not expect our audience to understand to whom we meant to refer.

Kripke (1972) makes other powerful arguments, besides the modal argument, against the view that names are disguised descriptions. His strongest argument, to my mind, is one about speaker knowledge. Here is a version of this argument: If the name "Plato" were synonymous with the description "the author of The Republic" then one would think that competent users of the name would have to know - at least implicitly - that Plato is the author of The Republic. However, it absurd to suppose that it is a condition on semantic competence with the term "Plato" that one know that "Plato" wrote The Republic.

I do not think the metalinguistic view succumbs to this argument about speaker knowledge. The knowledge that a person referred to by a name bears that name may well be part of every competent speaker's grasp of the meaning of the name. The only objection to this that I can see is the claim that children are able to use proper names without having sufficient conceptual resources to grasp descriptions like "the bearer of $N$." There are a few things to be said about this. First, the conceptual capacities of very young children may be extremely sophisticated, so that the empirical claim may simply be false: children might, from their first uses of proper names, be in a position to grasp (in some sense) the descriptions associated with names ${ }^{13}$ Second, even if children can use proper names without grasping the descriptions associated with them, this does not mean that the adult use of proper names is not descriptive in the way I have suggested. ${ }^{14}$ Third, it may be that children's use of proper names is in some way parasitic on adult usage or deferential to it, so that if adults did not use names as metalinguistic descriptions children would not be able to use them to refer people at all. These considerations show that the knowledge argument may not be successful against the metalinguistic view ${ }^{15}$

\footnotetext{
${ }^{12}$ Such views have a long tradition. Kneale (1962) explicitly advocates a metalinguistic view and Burge (1973) comes close to this view, though he treats names as predicates. More recently, Geurts (1997), Katz (2001) and Bach (2002) have endorsed versions of the view that names are metalinguistic descriptions.

${ }^{13}$ Bloom (2001) discusses what conceptual capacities children might need to learn the meaning of names and other words.

${ }^{14}$ Of course many who hold a descriptive account of names will not be happy with this response because they do not think that it is possible for there to be referring devices without descriptive content. They may, however, think that children associate different descriptions with names from those which adult users associate with them.

${ }^{15}$ See the literature cited in footnote 10 for discussion of how the metalinguistic view of names might avoid other challenges from Kripke and elsewhere.
} 


\section{Names as Descriptions under Modals}

Now that we have a reasonable account of the descriptive content of proper names in hand we can see whether it predicts that names are usually particularized descriptions. Recall that particularized descriptions are ones whose descriptive content is not commonly known to be uniquely satisfied by different individuals across a range of relevant possible circumstances. It seems to me that in most contexts metalinguistic descriptions must be particularized. For instance, it would require a very odd context to make it plausible that over an entire range of different possibilities there would always be a uniquely salient "Samuel" available, but without this being the same person in each situation. In many possible situations there is at least one person called "Samuel", but it is hard to see why there would always be one most salient such person.

In other words, metalinguistic descriptions are particularized definite descriptions in most contexts, since for most relevant classes of possible situations one cannot suppose there will be a different uniquely salient person satisfying the descriptive content in each situation. Supporting this view is the fact that it is quite hard to get descriptions of the form "the man bearing the name $N$ " to have narrow scope under metaphysical modals. Consider this sentence:

The president might not have been the man called "Havelock."

It is very hard to read "the president" in (6) as a wide-scope description while reading "the man called 'Havelock" " as a narrow-scope description-in other words it is hard to read the sentence as saying that the actual man who is now the current president might have had a different name. So, as we should expect given the conclusions I have reached, metalinguistic descriptions are extremely resistant to getting narrow scope.

Of course, in some contexts even metalinguistic descriptions will count as role-type descriptions. And in such cases, metalinguistic descriptions will be able to receive narrow-scope interpretations. Let us imagine a situation in which it is part of the common ground that there is always one, but not always the same, person bearing a particular name across different situations. Consider the name "M"- the name of the head of the British secret service in James Bond. "M" looks like a proper name, but if it is a proper name it is one which can get narrow scope with respect to modal operators:

John might have become M.

The names of superheros also exhibit this behavior. Consider Batman and Superman. In different circumstances different individuals may bear the superhero-title 16 Given this fact, it would be appropriate to talk about who might have been Superman or Batman. If proper names were just tags attached to particular individuals this behavior would be unexpected: We would not expect that the mere presentation of various relevant counterfactual situations across which different individuals lay claim to the same name would allow names to have narrow scope under modal operators. So names such as "M" and "Superman", unless they are somehow special, or differ in their semantic status from other proper names, provide support for the idea that names are semantically equivalent to definite descriptions, and, thus, in appropriate circumstances, can act as role-type descriptions. 17

The metalinguistic view has many further consequences, however, and we need to see whether they are also supported by our linguistic intuitions about how proper names work. For instance,

\footnotetext{
${ }^{16}$ Apparently there is a series of comic books set in the future in which different individuals are Batman, Superman, etc.

${ }^{17}$ Some, such as Soames (2002), argue that names like these are semantically distinct from other proper names.
} 
the view entails that names should always show the same potential scope as the definite descriptions that paraphrase them. Many have contested this point. The following examples, discussed in Abbott (2001), are supposed to show that names cannot be synonymous with metalinguistic descriptions:

Aristotle might not have been Aristotle.

Aristotle might not have been the man named "Aristotle."

The usual claim is that (8) has no true reading whereas (9) has a true reading.

It is worth pointing out, first of all, that neither sentence easily gets a sensible reading as a metaphysical modal assertion. This is evident from the fact that neither (8) nor (9) express the same thing as ?? nor is as obviously true:

$$
\text { Aristotle might not have been named "Aristotle." }
$$

This fact, of course, just follows from the earlier observation that particularized descriptions like "the man named Aristotle" in (9) do not have narrow-scope readings under metaphysical modals. A sentence like(9) is not assertible just by virtue of there being a metaphysically possible world where Aristotle is not named "Aristotle." Rather getting the narrow-scope reading of the description in (9) requires the common ground to include an entire range of relevant possible situations in which the descriptive content is satisfied by different individuals.

In certain contexts, a description such as "the man named 'Aristotle" "will be a role-type one. For instance, imagine it is commonly known that Greek law ensures that one and only one person is called "Aristotle" at a single moment of time. In this case there may be different relevant possible situations in which different people are uniquely called "Aristotle" and so the description "the man named "Aristotle", acts as a role-type one. Then, we might have an interest in who would have been called "Aristotle" if the actual person called "Aristotle" had not been born. Consider this sentence:

The person bearing the name "Aristotle" could have been a sailor. In these circumstances, it seems like it is quite easy to give the description a narrow-scope interpretation.

The crucial test for the metalinguistic descriptivist view is whether proper names also allow narrow scope in such circumstances. It is unclear what one should say about the sentence containing two proper names, (8), repeated below, when uttered in a context in which a Greek law of this sort is commonly known to be in effect. I think it is perhaps less good than the sentence yielded by replacing the proper names with two definite descriptions:

The man called "Aristotle" might not have been the man called "Aristotle."

But the difference between the felicity of these two sentences is very subtle, and both of these sentences are rather unnatural. A better example of a potential narrow-scope use of a proper name is a variation on (10):

Aristotle could have been a sailor.

If there is a Greek law stipulating that there is always one and only one Aristotle at any given time, then ?? seems like it has a reading on which the name gets narrow scope. I am not sure whether, with the narrow-scope reading, ?? is less natural than (10) or not. In general, I am not 
sure where the weight of intuitions lies in these cases ${ }^{18}$ However, I do not think the intuitions are weighty enough to form the basis of a serious argument against the view that names are semantically equivalent to metalinguistic definite descriptions.

We should not despair over the semantics of proper names just because our judgments of critical cases are hazy. The messiness of the data is not an obstacle to understanding proper names; it is just another piece of data in its own right. The question of whether proper names are particularized descriptions might not have a determinate answer. The right hypothesis may be that names are very similar to metalinguistic descriptions, but not exactly the same. That is, we may have a conventionally encoded bias towards particularized readings of the descriptive content that names bring with them.

What is important to see is that once we restrict our attention to the relevant situations-the cases where names should, on the descriptivist view, get narrow scope-the difference between names and descriptions becomes extremely subtle. Altogether the metalinguistic view of proper names does well at predicting what scope proper names will get under modal operators. If anything, it does better than standard non-descriptivist views which do not have many resources for explaining the fact that names sometimes do exhibit narrow scope under modal operators.

I certainly do not intend this as a serious defense of the metalinguistic view of proper names. While the view has its attractions, I am not inclined to think it is correct—if only for the reason that it is hard to explain why, out of the whole space of possible descriptive contents that names might have, names happen to have the metalinguistic content. 19 My main point here is just that considerations of scope do not force us to treat proper names as being semantically distinct from definite descriptions.

\section{References}

Abbott, B.: 2001, Definiteness and proper names: Some bad news for the description theory, Journal of Semantics 19, 191-201.

Bach, K.: 2002, Giorgione was so-called because of his name, Philosophical Perspectives 16, 73-103.

Bloom, P.: 2001, How Children Learn the Meaning of Words, MIT.

Burge, T.: 1973, Reference and proper names, Journal of Philosophy 70, 425-439.

Donnellan, K.: 1966, Reference and definite descriptions, Philosophical Review 75, 281-304.

Elbourne, P.: 2005, Situations and Individuals, MIT Press.

Geurts, B.: 1997, Good news about the description theory of names, Journal of Semantics 14, 319-348.

Katz, J.: 2001, The end of millianism, Journal of Philosophy 98, 137-166.

Kneale, W.: 1962, Modality de dicto and de re, in E. Nagel, P. Suppes and A. Tarksi (eds), Logic, Methodology and Philosophy of Science. Proceedings of the 1960 International Congress., Stanford University Press.

\footnotetext{
${ }^{18}$ One has to put aside the question-begging temptation-common in discussions of the modal argument- to label any narrow-scope use of a proper name as somehow special and, hence, irrelevant. The important thing to note in this context is that the narrow-scope uses of some definite descriptions, the ones which are usually particularized such as that in (10), also sound slightly odd.

${ }^{19} \mathrm{I}$ am inclined to think linguistic usage (in speech or in the head) does not determinately fix the descriptive content of names. Thus, there is no fact of the matter about what the descriptive content of names is.
} 
Kripke, S.: 1972, Naming and necessity, in G. Harman and D. Davidson (eds), Semantics of Natural Language, D. Reidel Publishing Co., Dordrecht, pp. 253-355.

Lewis, D.: 1983, Scorekeeping in a language game, Philosophical Papers, Vol.I, Oxford University Press.

Linsky, L.: 1983, Oblique Contexts, University of Chicago Press.

Nelson, M.: 2002, Descriptivism defended, Nous 36, 408-435.

Roberts, C.: 1989, Modal subordination and pronomial anaphora in discourse, Linguistics and Philosophy 12, 685-721.

Soames, S.: 1986, Incomplete definite descriptions, Notre Dame Journal of Formal Logic 27, 349-375.

Soames, S.: 2002, Rigid Designation, Oxford.

Stalnaker, R.: 2002, Common ground, Linguistics and Philosophy 25, 701-721.

Stanley, J.: 1997, Names and rigid designation, in B. Hale and C. Wright (eds), A Companion to the Philosophy of Language, Blackwell, pp. 555-585. 